\title{
Guillermo Borda: Profesor Honorario de la Universidad deLima
}

\author{
Augusto Ferrero
}

- Señor Rector de la Universidad de Lima,

- Sefnor Doctor Guillermo Borda,

- Sefor Vice Rector, seffores Decanos de las Facultades integrantes de nuestra Universidad,

- Señores profesores y alumnos:

DARA UNA AUTORIDAD que termina sus funciones en estos dias, I como es nuestro caso, nada más grato y honroso que participar en este acto académico organizado por nuestra Facultad de Derecho y Ciencias Políticas, por el cual conferimos la distinción de Profesor Honorario de la Universidad de Lima al ilustrísimo jurista argentino Guillermo Borda.

Nuestro homenajeado ha destacado como maestro universitario. abogado, magistrado, jurista, escritor de fina sensibilidad, legislador y político. Responde plenamente a la exigencia de los países que no han alcanzado aún su pleno desarrollo, los cuales citan a sus grandes hombres para que desarrollen las múltiples facultades que su sapiencia impone. De todas estas actividades, Borda ha sobresalido, sin duda, en el campo de la investigación jurídica, constituyendo su aporte a la doctrina comparable

(*) Discurso de orden promunciado por el Decano de ts Facultad de Derecho y Cienclas Potiticas de la Universidad de Lima, en la incorporación del doctar Guillermo Borda comn Profesne Honotario de la Universidad, el 14 de mayo de 1990. 
sólo con la tarea codificadora emprendida, el siglo pasado, por su compatriota Vélez Sarsfield en el campo legislativo.

Como autor, ha logrado desarrollar, en un Tratado de doce volúmenes, todas las disciplinas del Derecho Civil, en un esfuerzo monumental que para pretender conseguirlo en nuestro medio, nuestra Facultad ha debido encargarlo a un amplio grupo de estudiosos del Derecho, con la esperanza de conseguirlo en los próximos años. Su obra gigantesca es de consulta obligada para todos los abogados y estudiantes; pues está dirigida a dilucidar los grandes problemas del Derecho Privado. Con amor filial que destaca su calidad humana, este trabajo está dedicado a la memoria venerada de sus padres. Detenernos en el análisis de su vastísima producción serfa sumamente extenso. En esta ceremonia, nos limitaremos a aplaudir una vez más su contribución al pensamiento jurídico americano y la permanente renovación y dedicación del autor a la investigación; quien, en esta oportunidad, nos ha traído los dos nuevos tomos de Contratos, publicados en febrero del presente año.

Como político, fue Ministro del Interior, siguiendo la huella de su padre, el cual siendo un prominente líder del radicalismo, fue el primer gobernador electo de la Provincia de Córdoba. En coincidencia sumamente significativa para quien habla, el profesor Borda formó parte del gabinete ministerial del gobierno que condecoró a mi padre con la Gran Cruz de la Orden del Libertador San Martin de su patria.

Como legislador, Borda fue el gran mentor de la reforma del Código argentino de 1968. Formuló en ella incorporaciones importantes al Derecho rioplatense como la del abuso del derecho, la lesión, la teoría de la imprevisión y el divorcio por mutuo discenso.

Su origen familiar está vinculado al Perú. Tal como nos narra en un hermoso ensayo titulado "San Bartolo", nombre de su estancia criolla, su ascendiente, por ambas ramas, fue don Jerónimo Luis de Cabrera, fundador de la Provincia de Córdoba. Casado con la dama limeffa Luisa Martel, éste había fundado antes la ciudad de Ica, donde se estableció una de sus estirpes. Curiosamente, los descendientes de ésta en nuestro país tienen las mismas características que los de la estirpe argentina, a quienes el profesor Borda describe en el citado ensayo como gente que tenía "los ojos tan claros que debía taparse la vista con su abanico para que no le deslumbrara la luz", según le narraba su abuela.

Además de este origen andaluz, nuestro egregio homenajeado tiene 
ascendencia vasca por su madre, de donde quizás le viene esa perseverancia indesmayable para cumplir con sus propósitos e ideales.

El otorgamiento del título que le confiere hoy nuestra Universidad, además del reconocimiento que le debe América en razón de su producción jurídica, es también en gratitud de su participación en el Congreso Internacional organizado por el llustre Colegio de Abogados de Lima en 1988, que contó con el auspicio de nuestra Facultad, en el Congreso Internacional de Derecho Civil que convocamos en 1989 en nuestro Auditorio, con trasmisión simultánea en nuestras aulas magnas mediante sistema audiovisual, y en los cursos de extensión jurídica que iniciamos el día de hoy. Sumándose a este homenaje de las autoridades y del profesorado universitario, en actitud que demuestra noble agradecimiento y compenetración con la bibliografía jurídica, los alumnos de la promoción que egresa de nuestras aulas ha acordado que la misma lleve el nombre de Guillermo Borda.

El maestro Borda nos cuenta en el mencionado opúsculo biográfico cómo cuando el Vice Presidente de la República Argentina Elpidio González visitó invitado su estancia, se dirigió a su padre diciéndole: "Gracias, muchas gracias, doctor Borda", y cómo esas palabras le impresionaron vivamente y se convirtieron en muletilla en su casa por algunos meses. Cuando en nuestro Congreso Internacional del ano pasado el público se puso de pie para rendirle tributo a nuestro distinguido homenajeado, sentimos que eran esas palabras que deseaba expresar el auditorio, $y$ hoy día, en nombre de la Universidad de Lima, del Penú y del continente americano, queremos repetirlas como concreción de un sentimiento colectivo: "Gracias, muchas gracias doctor Borda". 